\title{
The Influence of Financial Accounting and Reporting on the Management of a Business Organization and A Case Study
}

\author{
Laman Guliyeva \\ Management (Accounting and Finance) Department, Ca' Foscari University of Venice, \\ Azerbaijan.
}

\begin{abstract}
The international financial crises experienced in recent years have led to the loss of confidence in capital markets. The understanding of organizational management has been developed to enable businesses to become reliable and robust institutions and to regain lost market confidence. Businesses need well-organized and well-functioning information systems to create reliable and robust structures. The most important of the business information systems is the accounting information system (MBS). The accounting information system plays an important role in the development of corporate governance understanding and taking the necessary measures in this direction and also in the presentation of the results of the application to the relevant persons.
\end{abstract}

As a result of the research, it has been determined that there is a significant positive relationship between corporate governance understanding and accounting information systems. In this context, attention should be paid to the accounting information system to successfully implement corporate governance understanding in enterprises and to offer solutions to problems. Because the accounting information system and corporate governance understanding create mutual power for effective management.

Keywords: Corporate Management, Accounting Information System, Accounting

\section{INTRODUCTION}

In today's business life, where we are witnessing a comprehensive and rapid change process, the problems that arise in the economic and social areas, and the international financial crises experienced, overshadow the reliability of financial information preparers (Atabey \&Y1lmaz, 2005). The crises and scandals experienced caused the interest groups to lose their trust in companies and brought organizational management to the fore as an information system and communication approach. Today, studies are carried out to restore the reliability of financial information preparers around the world. The understanding of organizational management, which came to the agenda as a result of these efforts, strives to transform institutions into a structure that is professionally managed and controlled within the framework of an information system and communication approach in line with the realization of the targets.

Accounting is a branch of science that records the financial transactions of the enterprises, classifies them, and conveys the results to the interest groups through financial statements. Because of this feature, accounting is a language that enables the business to be understood, and it is described as the "language of the business" in the literature (Dinç\& Kaya, 2006). The appreciation of information as a result of financial scandals caused radical changes in the accounting process, as in all business functions. Information in our age; is a fundamental resource for many businesses, economy and society. Because today, 
the basic competitive factor of businesses has transformed from tangible products to information that does not have a physical existence, to intellectual values. In addition, an increasing number of businesses are witnessing that quality information plays an important role in success.

Businesses should act in accordance with certain principles and rules and shape their activities within the framework of these rules to exhibit effective management. This approach is a fundamental element in the emergence of organizational management understanding. The basic element of organizational management understanding is knowledge. Especially reliable, accurate, transparent, accountable, fair, and responsible information, the place, and importance of appropriate, relevant, and timely information is extremely important in business management. Qualified information needed in business management can only be obtained from the accounting information system in a business where organizational management understanding and principles are valid. In this context, the accounting information system in enterprises ensures the production of the information needed to plan and evaluate their financial situation and to take the necessary measures (Xu, 2003).

\section{ORGANIZATIONAL MANAGEMENT APPROACH, PRINCIPLES, AND IMPORTANCE}

The fact that business management ceased to be a technical regulation and area of work determined by professional managers and transformed into a whole of processes determined together with social actors, increased the importance of the concept of organizational management (Çukurçayır, 2002). The concept of organizational management, which is used as the equivalent of the term "organizational management" in the Turkish literature, increases the value and efficiency of the company by being aware of the responsibilities of the activities of the companies to the parties, ensures that the company achieves the previously planned targets against its partners, shareholders and employees, It is defined as a system that works within the framework of (Senver, 2005). According to the OECD, organizational management in a narrow sense; It has been defined as "a system in which companies are directed and controlled", in a broader sense "a ball of relationships between companies' management, board of directors, shareholders and other interest groups" (OECD, 2004). Successful organizational management practices in businesses are not only a good protector that prevents waste of resources, but are also seen as an important element in financial transparency, controlling partnership activities, social responsibility awareness, and protecting ethical rules and investors in many countries (Shelton, 1998). . There is not a single standard application of organizational management understanding, and there may be differences in practices from country to country. These differences are shaped according to the economic and social change experienced in the country and the values and principles that emerged due to this change. Discussions on organizational management have led to the formation of international literature. The principles and principles created under various names such as code, codex, guide (guidelines) have an important place in the formation of this literature (Doğu, 2003). On the other hand, organizational management in the global framework is shaped around four generally accepted main principles. These; transparency, accountability, fairness, and responsibility.

\section{ACCOUNTING INFORMATION SYSTEM AND ITS IMPORTANCE FOR BUSINESSES}

The accounting information system is aimed at achieving the goals of the enterprise methodically and systematically, and information processing systems constitute the backbone of the accounting information system. Information processing systems play a role in creating the detailed design of the accounting information system and putting the system into practice. At this stage, starting from the planning of the necessary operations, defining the subsystems, determining the information processing activities required for the system, performing coding operations that will provide convenience in the system, developing the databases and documents to be processed in the system, selecting the equipment suitable for the system, renewing the organizational structure and system of the enterprise. Detailed 
design of the accounting information system is completed with the preparation of documents describing, introducing, and showing what it will do. While businesses create an accounting information system suitable for them, they have to fulfill the necessary steps for the system (Sürmeli and Others, 2001). In other words, businesses that decide to establish an accounting information system should make the detailed design and application of the system.

There are several principles that should be taken into account in establishing the accounting information system in businesses. These principles are briefly explained below (Karacaer\&İbrahimoğlu, 2003).

Eligible Cost Principle: This principle states that attention should be paid to cost-benefit analysis in the establishment and operation of the accounting information system.

Reporting Principle: This principle states that the accounting information system should regularly prepare financial statements and other reports that reflect the truth.

Human Factor Principle: It states that the personnel who will operate the accounting information system must have a sufficient number of professional competencies.

Organizational Structure Principle: In the accounting information system, it means having flawless personnel management, appropriate distribution of authorities and responsibilities, and job descriptions.

The Principle of Being Open and Understandable: It states that the accounting information system should be easily understandable and clear. As per this principle, a system should not need to be complex to be efficient.

Data Collection and Processing Principle: It refers to the regular recording of the data received in the accounting information system, to produce various information by processing these records and to store this information with the help of documents. This principle is briefly defined as input-process-output.

\section{ORGANIZATIONAL MANAGEMENT APPROACH AND ACCOUNTING INFORMATION RELATIONSHIP}

With a fair, impartial, and honest approach, taking into account the interests of not only certain individuals or groups but also all interest groups, from accounting, which records and reports business events in an organized structure and provides information about the life and commercial success of the business; It is expected to contribute to the economic, legal, moral and responsibility initiatives of the enterprise. Today, businesses are asked to present the information they need to the relevant parties in an understandable manner, with a transparent and accountable approach, in a timely manner with an understanding of responsibility, as well as accurate and reliable accounting records (Demir, 2005). In this context, expectations from the accounting information system of the enterprise can only be possible with the organizational management approach valid in the enterprise (Özkol, Çelik, \& Gönen, 2005).

Organizational management mechanisms such as the board of directors and the audit committee, which play a role in the implementation of the organizational management understanding in the enterprise, need to provide support from the accounting information system. Establishment and continuity of organizational management practices that will ensure the continuity of enterprises and ensure their long-term profitable and healthy growth will be possible with the information obtained from the accounting information system to a great extent (A. Aysan, 2007). The benefit that can be obtained from the production of knowledge can be at higher levels only if the information is produced in a reliable, timely manner and accordance with the needs. Information with these qualities can 
be obtained from the accounting information system of an enterprise, where organizational management understanding and principles are valid.

The understanding of organizational management in businesses also determines the effectiveness of the accounting information system. In other words, organizational management understanding plays a primary role in the production of healthy information by the accounting information system in enterprises (Xu, 2003). For example, under the transparency principle of the organizational management approach, the accounting policies applied and the activity reports prepared are required to be disclosed to the public under the facts. Based on the idea that the strategic value of information is hidden in its quality, it is understood that the organizational management understanding provides quality to the information produced by the accounting information system. An accounting information system operating based on organizational management principles in businesses can play a role in achieving organizational success as an important tool that guides mental capital (Özdemirci\& Cengiz, 2007).

The information obtained from the accounting information system of the company can be useful for decision-makers only if the information is produced from the accounting information system of an enterprise where organizational management principles apply. Compliance of the information obtained from the accounting information system in businesses with the desired organizational management principles is closely related to the willingness and success of the understanding to be applied by the management within the company. Organizational management implementation mechanisms should be based on the principles of understanding within the system to fulfill the functions expected from the accounting information system. Otherwise, problems may occur in the production of information and transmission of information. Today, with the separation of ownership and control created by the modern company, an asymmetric information problem may arise between the parties. The asymmetric information problem causes the problem of not being able to act together and some costs arise depending on this problem. In an information system with asymmetric information, investors may have less information about management practices. This lack of knowledge also negatively affects management practices in businesses. Among the stakeholders, timely and fluent financial information can be provided to related parties through the accounting information system. Organizational management understanding; will be able to solve the problem of information asymmetries arising from the differentiation of interest between managers, investors, and creditors through the accounting information system that is responsible, transparent, accountable, and capable of providing simultaneous information based on the principle of equality.

\section{CASE STUDY: NIGERIAN BREWERIES PLC}

Source of Data. The majority of the secondary research evidence gathered by the researcher came from library resources. These reference materials were used to thoroughly analyze Nigerian Breweries plc's facts and monitoring elements. The following academic libraries were consulted to collect secondary data:

a. Nigerian Central Bank

b. National Library, Enugu Freedom Architecture

c. Enugu Campus Library of the University of Nigeria

In the overview, the following data sets were gathered:

- Information gleaned from an oral interview and library resources

- Information gleaned from a collection of previous relevant research projects

The research instruments used by the researcher to gather whatever data is required are referred to as data collection. Questionnaires, interviews, and library studies were used as research tools in this study. The researcher used questionnaires because they are the most practical, cost-effective, and simple means of gathering knowledge about incidents. They also assisted in the collection of reliable data. The researcher used an interview schedule 
because it was helpful in following up on an unpredictable finding in order to confirm a new approach or problem motivation of respondents and their explanations for answering in the way they did.

\section{METHOD OF DATA ADMINISTRATION AND QUESTIONNAIRE}

A questionnaire is a collection of deliberately chosen and arranged questions and statements that are posed to respondents in order to elicit the knowledge or evidence needed to test a hypothesis. The answers to the questions posed in the research issue will be given by this test.

The questionnaires were given out based on a non-random sampling of the people in the survey. This was achieved in such a manner that the optimal outcome was obtained. There are a total of twenty-seven (27) questions in the questionnaire. The questions are either closed-ended, in which respondents are only expected to choose between choices, or openended, in which respondents are expected to express themselves easily without being forced to choose between certain options.

I translated the data collected into simple percentages. This was done so that an inferential argument about any partnerships could be made. The theory was evaluated using the chisquare (x2) test statistic, which determines the magnitude of the difference between observed frequencies. The chi-square formula was used to calculate the results.

Where: of - observed frequency

$$
X^{2}=\frac{£(o f-e f)^{2}}{e f}
$$

ef - expected frequency

To fulfill the study's targets, the research theory would be put to the test. Each of the four hypotheses was checked, and the findings were used to decide if the alternative hypothesis could be accepted or denied in each situation. A critical value of chi-square is calculated from the chi-square table based on the degree of freedom (df) and the amount of trust obtained (x2). If the critical value ( $\mathrm{x} 2$ e) derived from the table of chi-square is greater than the chi-square value (x2) calculated using the formula, reject the null hypothesis; otherwise, do not reject the null hypothesis.

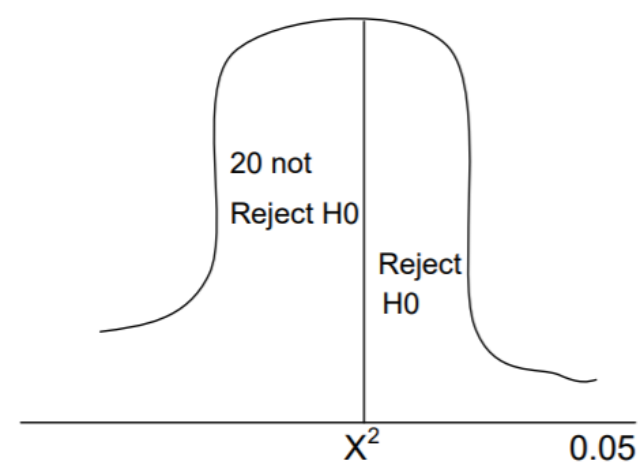

The decision rule is summarized by the curve drawn above. Mathematically the decision rule could be stated thus:

Reject HO if $\mathrm{x}^{2}>\mathrm{x}^{2} \mathrm{e}$

Accept HO if $x^{2}<x^{2} e$

When $\mathrm{x}^{2}=$ chi-square value obtained from the chi-square table or simple known as the critical value.

$\mathrm{X}^{2}=$ the calculated chi-square value the table value which is represented by X $2=3.841$ 
Table 1. Number of questionnaires issued and the percentage returned.

\begin{tabular}{|c|r|r|r|}
\hline Respondents & Issued & Returned & Percentage (\%) \\
\hline Accountants & 10 & 10 & 38.5 \\
\hline Auditors & 5 & 5 & 19.2 \\
\hline Analysis & 11 & 8 & 30.8 \\
\hline Total & 26 & 23 & 88.5 \\
\hline
\end{tabular}

The answers to questions NO 14, 18, and 19 of the questionnaire were used to test the above hypothesis. The relevance level. At a 5\% degree of relevance, the theory was checked. Test of Statistics: The test statistics employed is the chi-square $\left(\mathrm{x}^{2}\right)$ distribution.

Degree of freedom, $\mathrm{df}=(\mathrm{r}-1)(\mathrm{a}-1)$

$$
\begin{aligned}
& =(2-1)(2-1) \\
& =1
\end{aligned}
$$

Computation of critical value $\left(\mathrm{x}^{2}\right.$ e $\left.0.05=3.841\right)$

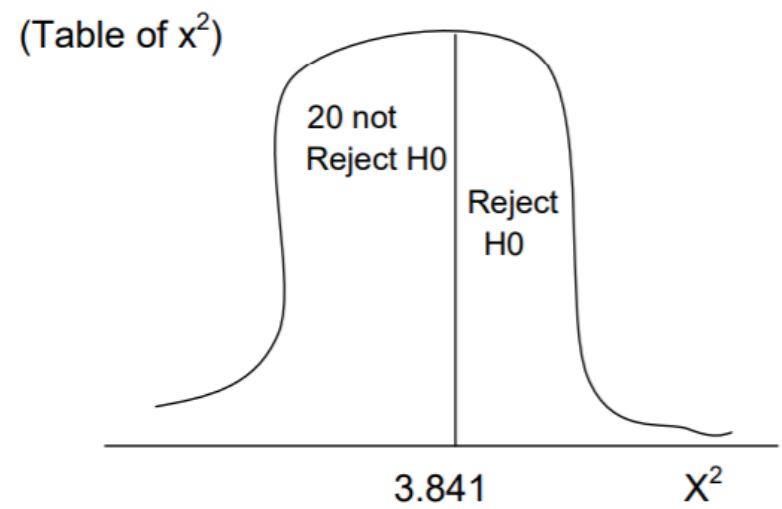

Reject Hypothesisif $\mathrm{X}^{2}$ calculated $>3.841$

Accept Hypothesis if $\mathrm{X}^{2}$ calculated <3.841

Computation of data for validation of hypothesis

\begin{tabular}{|l|l|l|l|}
\hline Questions & Yes & N0 & Total \\
\hline Do you think that the financial report has enough & 12 & 11 & 23 \\
\hline $\begin{array}{l}\text { Do you think that the company has imbibed objectivity } \\
\text { in its reporting? }\end{array}$ & 17 & 6 & 23 \\
\hline $\begin{array}{l}\text { Do you think that the stakeholders desire more } \\
\text { information than the organization is giving? }\end{array}$ & 9 & 14 & 23 \\
\hline
\end{tabular}


Table 2.Computation of Calculated Chi-Square Values

\begin{tabular}{|l|l|l|l|l|}
\hline of & ef & (of-ef) & $($ of-ef) & $\frac{\text { (of-ef) }^{2}}{\text { ef }}$ \\
\hline 12 & 12.67 & $(0.67$ & 0.4489 & 0.0354 \\
\hline 11 & 10.33 & 0.67 & 0.4489 & 0.0435 \\
\hline 17 & 12.67 & 4.33 & 18.7489 & 1.4798 \\
\hline 6 & 10.33 & $(4.33)$ & 18.7489 & 1.8149 \\
\hline 9 & 12.67 & $(3.67)$ & 13.4689 & 1.0631 \\
\hline 14 & 10.33 & 3.67 & 13.4689 & 1.34689 \\
\hline Total & - & - & - & 5.80219 \\
\hline
\end{tabular}

The test statistics have fallen into the rejection area since the calculated chi-square value of 5.80219 is more than the critical or table value obtained i.e. 3.841.

\section{CONCLUSIONS}

The understanding of organizational management reveals a superstructure surrounding all the activities of the companies and emphasizes the necessity of directing within the framework of certain principles and rules against all interest groups involved. The understanding of organizational management includes principles related to the concepts of public disclosure and transparency. Within the framework of these principles, it is foreseen that companies establish an information policy for shareholders and disclose the information to be included in the periodical financial statements and reports to the public in an accurate, clear, and transparent manner by adhering to these policies. In this context, the validity of an effective organizational management approach in businesses depends largely on the establishment of a good accounting information system. Because the understanding of organizational management and implementation mechanisms (board of directors, audit committee) will provide power from a reliable accounting information system. The accounting information system provides extremely valuable information to business management to the point that decision-making groups about the business can reach the right decision. The accounting information system aims to provide the necessary information to ensure the control of the business actions by fulfilling the management responsibility of the management on the assets and to plan the business actions for the future (Sürmeli and Others, 2001). In other words, the accounting information system is the constant source of today's modern, economic and financial world and is the main contributor to the progress of businesses towards being more efficient and fairer (Degos, 2008).

As a result of the analysis, no relationship has been determined between the "eligible cost principle" of the accounting information system and the principles of organizational management. It is accepted that establishing a detailed information system in the accounting information system will not always be effective. That is, it is thought that a detailed information system can lead to cumbersome and increase costs. For this reason, it is accepted that it would be more beneficial to establish a low-cost information request instead of a detailed information system in enterprises, but that produces all the requested information in full and on time. There is no cost concern in the principles of organizational management understanding. Therefore, it is the expected result that the accounting information system does not find a relationship between the eligible cost principle and organizational management principles. In addition, in the analysis, no relationship was 
determined between the "human factor" principle of the accounting information system and the principles of "fairness and equality" and "transparency", which are among the organizational management principles.

\section{References}

[1]. Atabey, N.A., Y1lmaz, B., \& Ay, M. (2005). "Corporate management" in terms of social responsibility concept of accounting in the process of joining the European Union IV. Central Anatolia Business Congress, TOBB University of Economics and Technology, Ankara.

[2]. Baker, C. R., and Wallagey, P.(2000). The future of financial reporting in europe: 1 ts role in corporate governance. The International Journal of Accounting, Vol. 35, No. 2, 173- 187

[3]. Bayri, O. (2006). The role and importance of accounting in the concept and culture of accountability and accountability. Accounting Science World Journal (MÖDAV), Volume: 8, Number: 2, 125-14.

[4]. Bushman, R.M. ve Smith, A.J. (2001). Financial accounting information and corporate governance. Journal of Accounting and Economics, Vol: 32, 237-333

[5]. Chung, K., Wright, P. and Kedia, B. (2003). Corporate governance and market valuation of capital and R\&D investments. Review of Financial Economics, 12: 161 - 172.

[6]. Degos, J.G. Is the future of accounting compatible with the accounting of the future?, Accounting and Finance Magazine (mufad), issue: 37, January 2008, 205-221

[7]. Gökdeniz, Ü. (2005). Approach to accounting information system in businesses. Accounting and Finance Magazine (MUFAD), No: 27, 86-93

[8]. Lucas, H.C. (1975). The Use of an accounting information system, action and organizational performance. Accounting Review, 50: 4, 735-746

[9]. Aborode, R. (2006). A Practical Approach to Financial Accounting, Lagos:Master Stoke Consulting

[10]. Alexander, D. and Britton, A (1996). Financial Reporting, International, London:Thomas Business Press. 